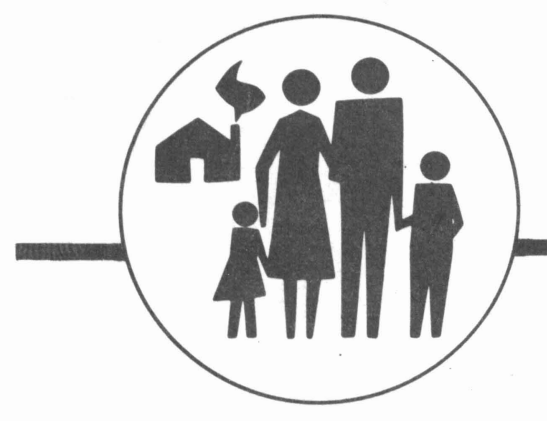

\title{
FRUTAS y VEGETALES RICOS EN VITAMINA C
}

una buena selección para la familia que desea economizar

Estos alimentos son ricos en Vitamina $\mathrm{C}$ y casi siempre son buenas compras
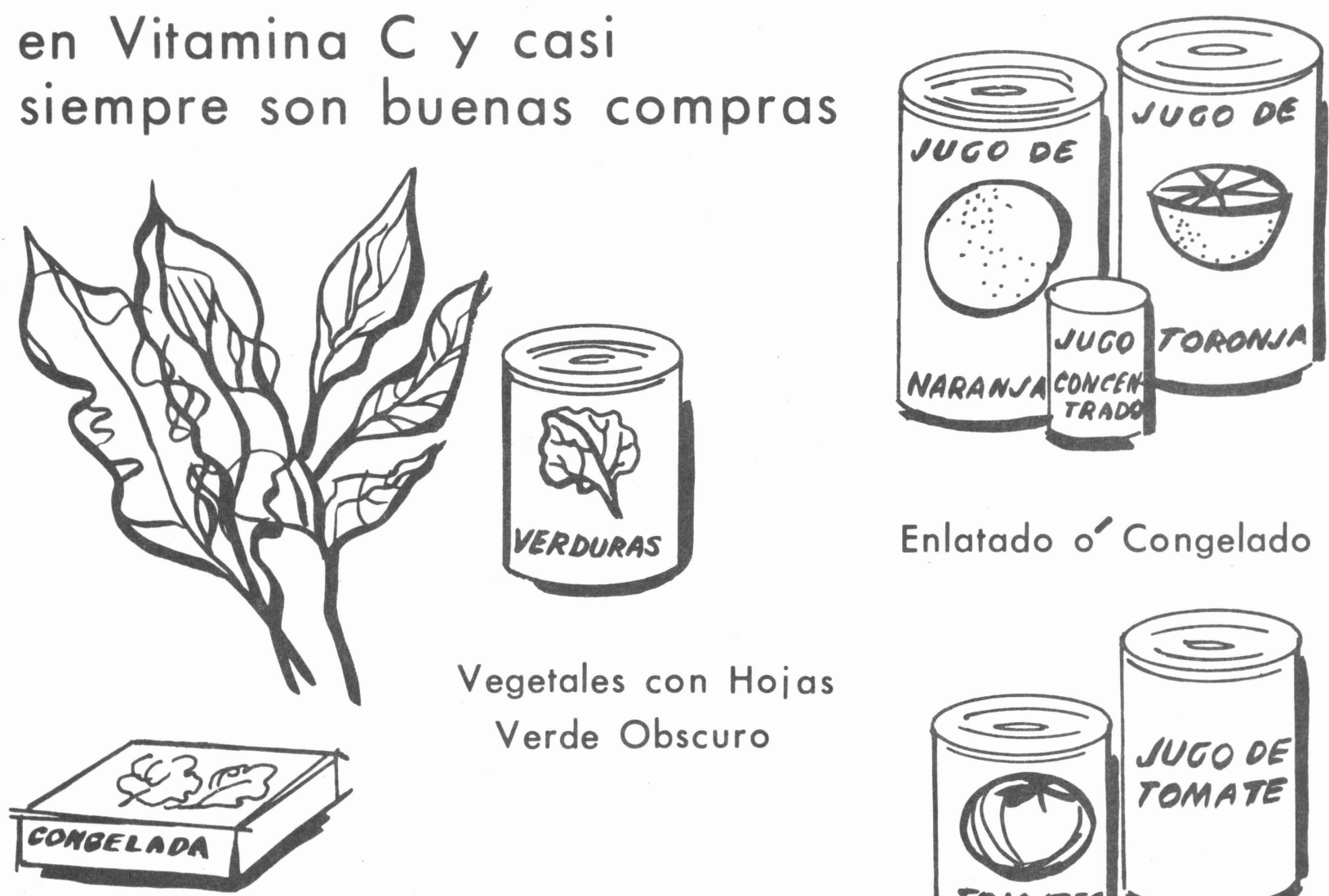

Enlatado o' Congelado

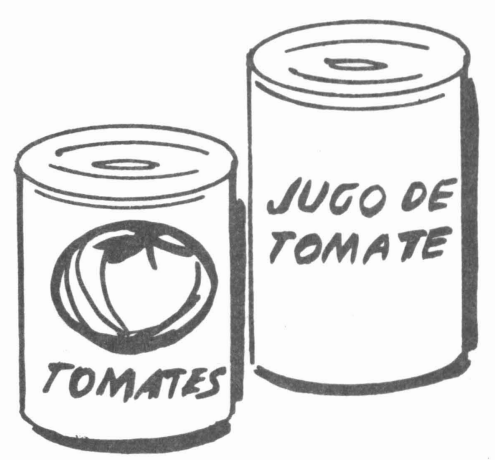

Papas y

Camotes
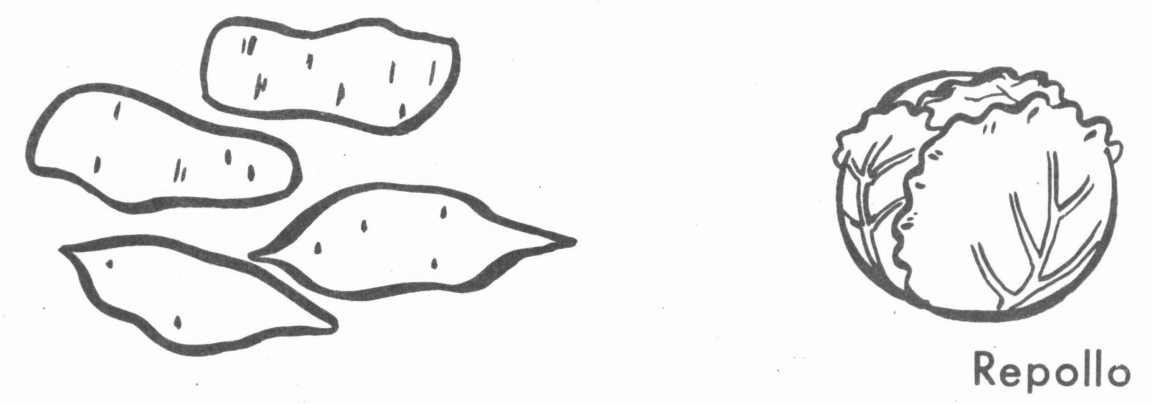

CONSUMA DIARIAMENTE UNO O'MAS DE LOS ALIMENTOS RICOS EN VITAMINA C 
Algunos de los Alimentos Ricos en Vitamina C solamente son Compras Buenas durante ciertas temporadas del año

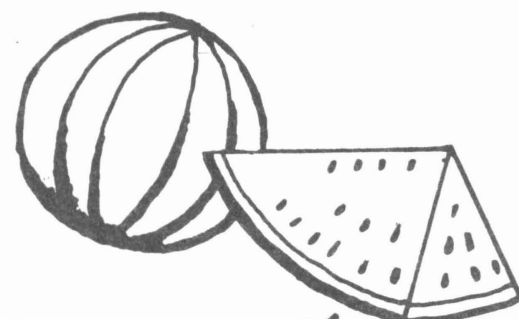

Melones y Sandía

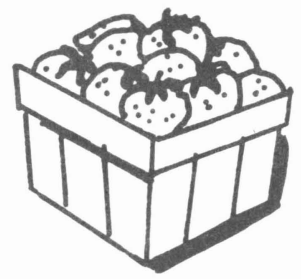

Fresas
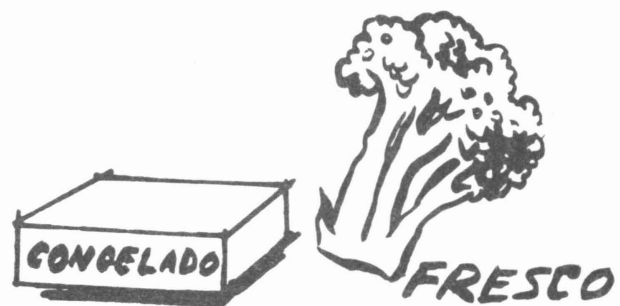

Bróculi (Brecol)

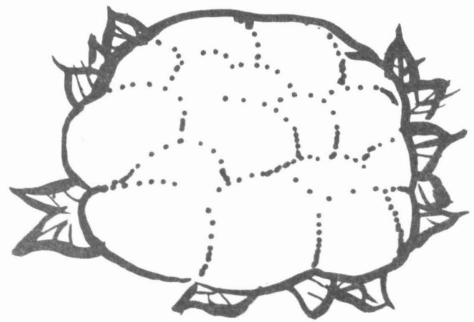

Coliflor

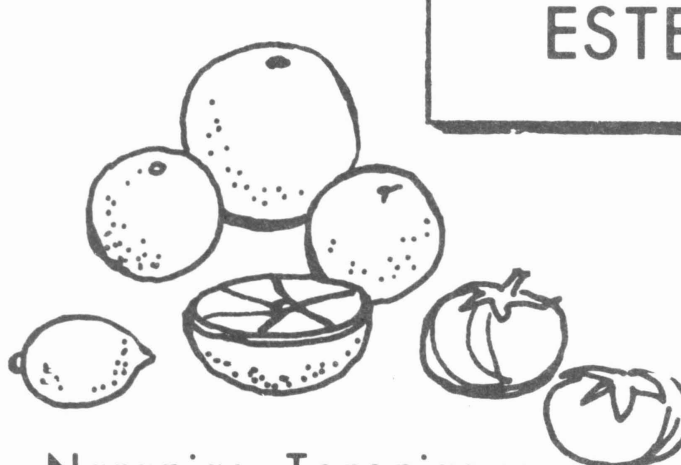

Naranjas, Toronjas y

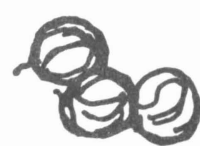

Colecitas de Bruselas (Brusse1 Sprouts)

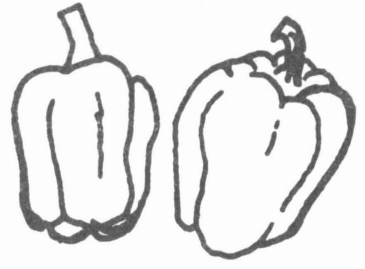

Chiles

Verdes y Rojos otras Frutas Cífricas, y Tomates

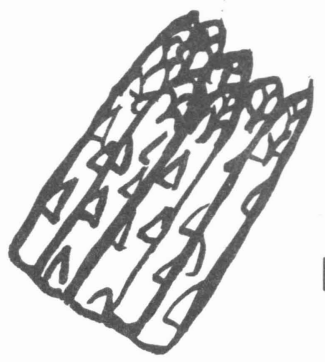

Espárrago

La Vitamina $C$ se destruye si cocinamos los alimentos por largo rato
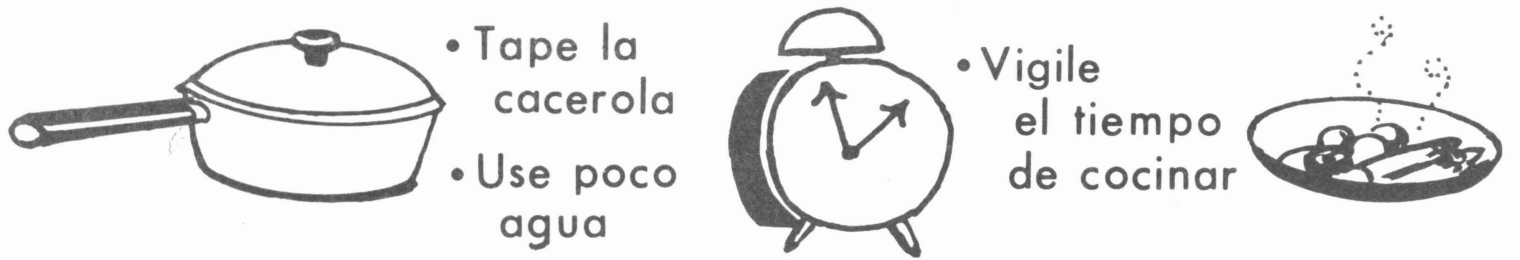

- Sirva

inmediatainente

\section{Cocine solamente hasta que se ablanden}

Adapted by permission of the U. S. Department of Agriculture, Consumer and Marketing Service, Agricultural Research Service. Translation adapted by Mina Valdez, Extension assistant foods and nutrition specialist, ENP-Youth, Texas A心M University.

Educational programs conducted by the Texas Agricultural Extension Service serve people of all ages regardless of socio-economic levels, race, color, sex, religion or national origin. 